\title{
IDENTIFICACION Y DESCRIPCION DE DIECINUEVE ESPECIES FORESTALES DEL BOSQUE HUMEDO TROPICAL (bh-T) COLONIA ANGAMOS (RIO YAVARI) Y JENARO HERRERA
} BALUARTE VASQUES JUAN ROMMEL $\quad\left({ }^{*}\right)$
AROSTEGUI VARGASANTONIO

\section{RESUMEN}

El presente artículo reporta un avance del estudio identificación y colección de maderas de las especies forestales de selva baja, que forma parte del proyecto Binacional Peruano-Brasilero sobre estudios básicos y aplicados de las maderas de la selva baja. En este estudio se señalan los pasos seguidos para la identificación de 19 especies forestales colectadas, siendo 8 de Colénia Angamos (Río Yavarí) y 11 de Jenaro Herrera.

A simismo, se presentan los resultados obtenidos por los investigadores que colaboraron en la identificación. Estos resultados tienen carácter oficial, porque están avalados por reconocidos especialistas en el campo de la botánica taxonómica. También se incluye el resumen dendrológico, hábitat y distribución de las especies identificadas.

En base del estudio efectuado se logró identificar plenamente 19 especies forestales de la amazonía peruana. 


\section{ABSTRACT}

Nineteen timber species were coilected in Jenaro Herrera and Colonia A ngamos.

A brief dendrological description including habitad references and geographical distribution in provided for each species.

\section{INTRODUCCION}

Uno de los problemas fundamentales que impiden el desarrollo del sector forestal es el desconocimiento de las especies forestales más abundantes.

Los bosques de la amazonia peruana presentan una composición florística muy compleja 0 altamente heterogénea, estimándose que existen al rededor de 2,500 especies forestales diferentes, de las cuales sólo están debidamente reconocida cerca de 600 especies; por ello, es preciso identificar esta gran cantidad de especies y determinar sus usos para integrarla al contexto de las especies útiles para su comercialización.

A simismo, esta gran diversidad de especies ignoradas no permite un aprovechamiento racional e integral de uno de nuestros más abundantes recursos naturales renovables, ya que este reducido número de especies conocidas son insuficientes para trazar políticas de desarrollo forestal a corto y mediano plazo.

La identificación de las especies forestales es un requisito indispensable en el planeamiento, desarrollo y ejecución de casi todas las labores dasonómicas, jugando un papel importante, tanto en el plan de aprovechamiento integral de los bosques como en la comercialización de productos forestales. Todas las labores forestales están directa 0 indirectamente relacionadas con la identificación de las especies vegetales.

Este estudio ha tenido como objetivo la identificación y descripción de 19 especies forestal es del bosque húmedo tropical (bh-T). 
Los responsables de la identificación de cada una de estas instituciones fueron: por la UNAP, el Dr. Franklin Ayala Flores; por la UNMSM, el Dr. Filomeno Encarnación y por el INPA, el Ing. Raúl Noriega Montero y el Dr. Juan Revilla Cárdenas.

Los resultados de la identificación fueron cotejados con la participación de los tres especialisas antes mencionados; en esta reunión se analizó la identificación de cada una de las especies en estudio, con. el objeto de obtener un consenso general en la identificación, lo que repercutió en una mayor confiabilidad de los resultados.

\section{RESULTADOS Y DISCUSION}

\section{A. RESULTADOS DE LA IDENTIFICACION DE LAS 19 ESPECIES}

Los resultados de la identificación de las 19 especies forestales estudiadas se muestran en los Cuadros $N$ N 1, 2, 3 y 4, avalados por los responsables de las diferentes instituciones colaboradoras que han intervenido en la identificación.

En base de los datos de estos Cuadros y del consenso general en la identificación se obtuvo un resultado final, el mismo que se indica en el Cuadro $\mathrm{N} \cong 5$.

\section{REVISION DE LITERATURA}

RIOS, (16): indica que la identificación o determinación botánica consiste en el conocimiento del nombre científico de las plantas, labor que se lleva a cabo consultando claves, floras, manuales, muestras de herbario, jardines botánicos, arboretos y a través de la propia experiencia del investigador. Sobre los hábitos de floración y fructificación, este mismo autor expresa que son fenómenos cíclicos y a veces pasan largos períodos antes que se produzcan flores y frutos.

BUDOWSKY, (9): sostiene que pocas personas pueden dar el nombre científico de un árbol en el campo; por lo que la recolección y el envío de muestras adecuadas a un especialista, para su identificación, constituye el método mas seguro, pero requiere de mucho tiempo e investigación.

Sin embargo, JIMENEZ, (11): señala que los dendrólogos han desarrollado habilidades para identificar los árboles, por medio de las características simples macroscópicas de los órganos vegetativos; es obvio que dichas características permiten llegar, a veces, hasta la determinación de la familia o el género. Sin embargo, después 
de que una especie haya sido correctamente clasificada y descrita y que se haya depositado en un herbario, es posible hacer identificaciones confiables en base a especímenes estériles.

SALAZAR, (17): indica que para identificar nuestras especies forestales, es necesario emplear un método de colección que asegure la perduración de los especímenes en el herbario, carpoteca y xiloteca; debe acompañar a la colección datos adicionales en ficha o formularios dendrológicos, de tal modo que facilite su descripción e identificación posterior. Los datos deben incidir en las características vegetativas de las plantas.

Agrega, también, que la metodología se puede resumir de la siguiente manera: selección y marcado de los árboles; colección del material botánico; preservación, prensado y secado de los especímenes con hojas, flores y/o frutos; identificación y montaje de especímenes; acomodo de especímenes de herbario y carpoteca; preparación de las muestras de madera; tratamiento de las muestras de madera para xiloteca y elaboración de fichas y formularios para la descripción de los árboles.

\section{MATERIALES Y METODOS}

\section{A. LUGAR DE COLECCION}

Las zonas seleccionadas para la colección de las muestras botánicas fueron las localidades de Colonia Angamos y Jenaro Herrera; la primera se encuentra en la margen izquierda del río Yavarí, distrito de Yaquerana, provincia de Maynas, departamento de Loreto, estando ubicada geográficamente sobre las coordenadas 050 10' de Latitud Sur y 72은 L ongitud Oeste.

L a segunda se encuentra ubicada al suroeste de la ciudad de Iquitos, margen derecha del río U cayali, distrito de Sapuena, provincia de Requena, departamento de Loreto; geográficamente está sobre las coordenadas 04055' de L atitud Sur y 73 40' de L ongitud Oeste.

A mbas localidades están distanciadas $100 \mathrm{Km}$. en línea recta, una de la otra, y forman parte de la formación vegetal bosque húmedo Tropical (bh-T), ONERN (14). 
Según MARENGO (13): Jenaro Herrera está situada a una altura de 180 m.s.n.m. y cuenta con una temperatura media anual de $24.73^{\circ} \mathrm{C}$, siendo la precipitación media anual de 3,234 mm. Agrega, también, que en Colonia A ngamos la precipitación media anual es de 2,298 mm. y la altitud de 125 m.s.n.m. El suelo predominante es para ambas localidades de tipo arcilloso.

\section{B. MATERIALES USADOS}

Entre los principales materiales utilizados se puede mencionar los subidores de púas, tijeras telescópicas, tijeras podadoras manuales, equipo de prensado, bolsas de polietileno, sustancias anti-defoliantes, libreta de apuntes, binoculares, regla y equipo de fotografía. La relación detallada se halla en BALUARTE (2).

\section{METODO}

\section{Ubicación y marcado de árboles}

La ubicación y marcado de los árboles se efectuó con el apoyo del matero del Centro de Investigaciones Jenaro Herrera. De cada una de las especies seleccionadas se ubicaron y marcaron cinco árboles con muestras botánicas completas, es decir, con flores y/o frutos; en caso contrario, se ubicó y marcó un sexto árbol como testigo para la posterior colección de muestras botánicas fértiles. Los árboles fueron marcados con pintura al aceite, de color amarillo, asignándole a cada uno de ellos un número de la serie natural (Foto $N$ ㅇ 1)

\section{Control fenológico de las especies}

Los árboles marcados de las especies en estudio fueron inspeccionados periódicamente, con el propósito de tomar datos sobre las diferentes fases fenológicas, o sea, los estados que comprenden la foliación, floración, fructificación, maduración y semillación. En cada una de las inspecciones, los árboles fueron observados a simple vista o con ayuda de binoculares.

\section{Colección del material botánico}

Para la colección del material botánico se tomaron cinco muestras para cada árbol, para ello se requirió el uso de equipo subidor. Los datos concernientes al árbol fueron recopilados en formularios dendrológicos de campo, los datos complementarios fueron anotados en una libreta de campo. 


\section{Tratamiento, prensado y secado de muestras botánicas}

Para el tratamiento de las muestras botánicas se utilizó la solución FAA (Formol, Alcohol y A gua). (F oto № 2). El secado se efectuó al sol y en estufas a kerosene, previo acomodo y prensado.

\section{Identificación}

La identificación preliminar en el bosque se hizo en base a las características morfológicas y organoléptica del árbol, contando con el apoyo del mal ero; luego, las muestras botánicas fueron comparadas con los especímenes que se encuentran en el Herbarium Herrencense.

Posteriormente, estas muestras botánicas fueron remitidas para su identificación final al Herbaríum Amazonense de la UNAP, al Museo de Historia Natural Javier Prado de la UNMSM y al Herbarium del Instituto $\mathrm{N}$ acional de Pesquisas A mazónicas de $\mathrm{M}$ anaos-Brasil. 


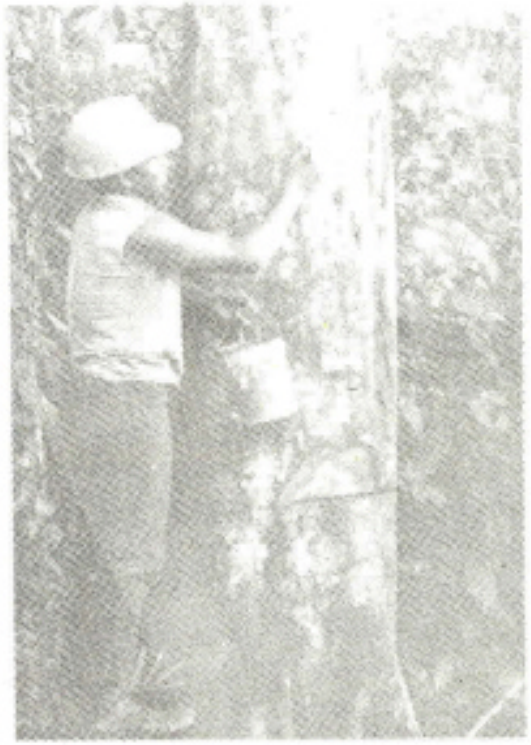

\section{FOTO № 1}

Marcado de los árboles con pintura al aceite, de color amarillo

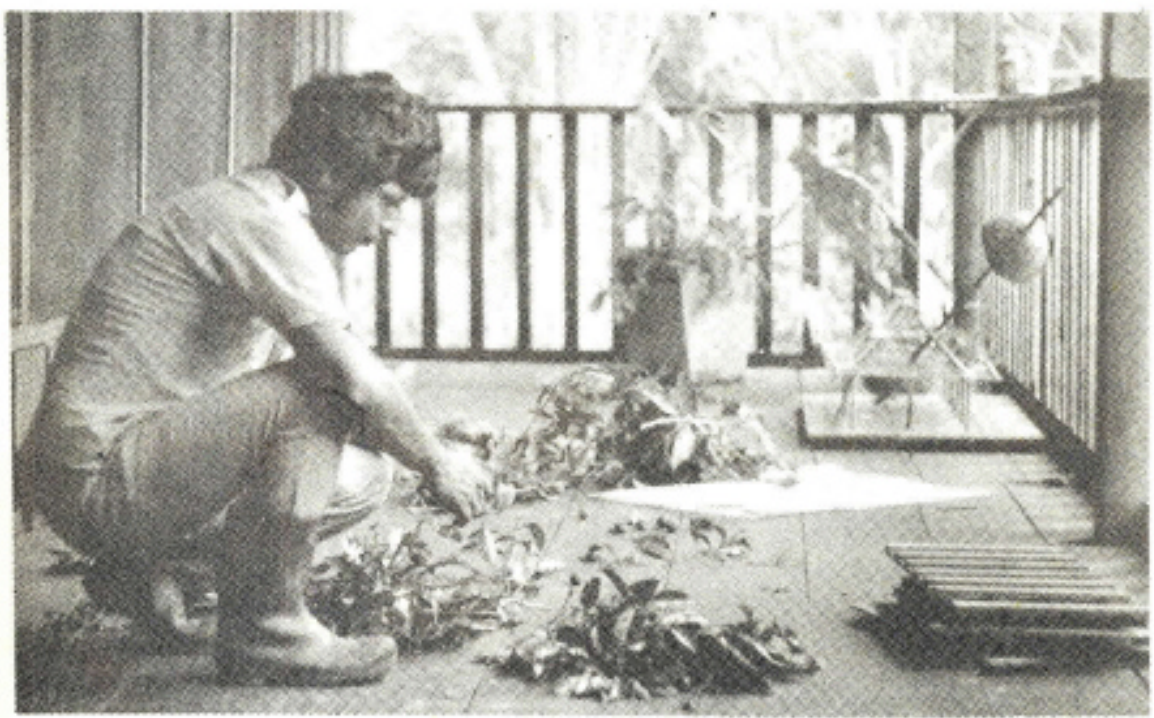

FOTO N 22

Preparación de las muestras botánicas para el prensado 


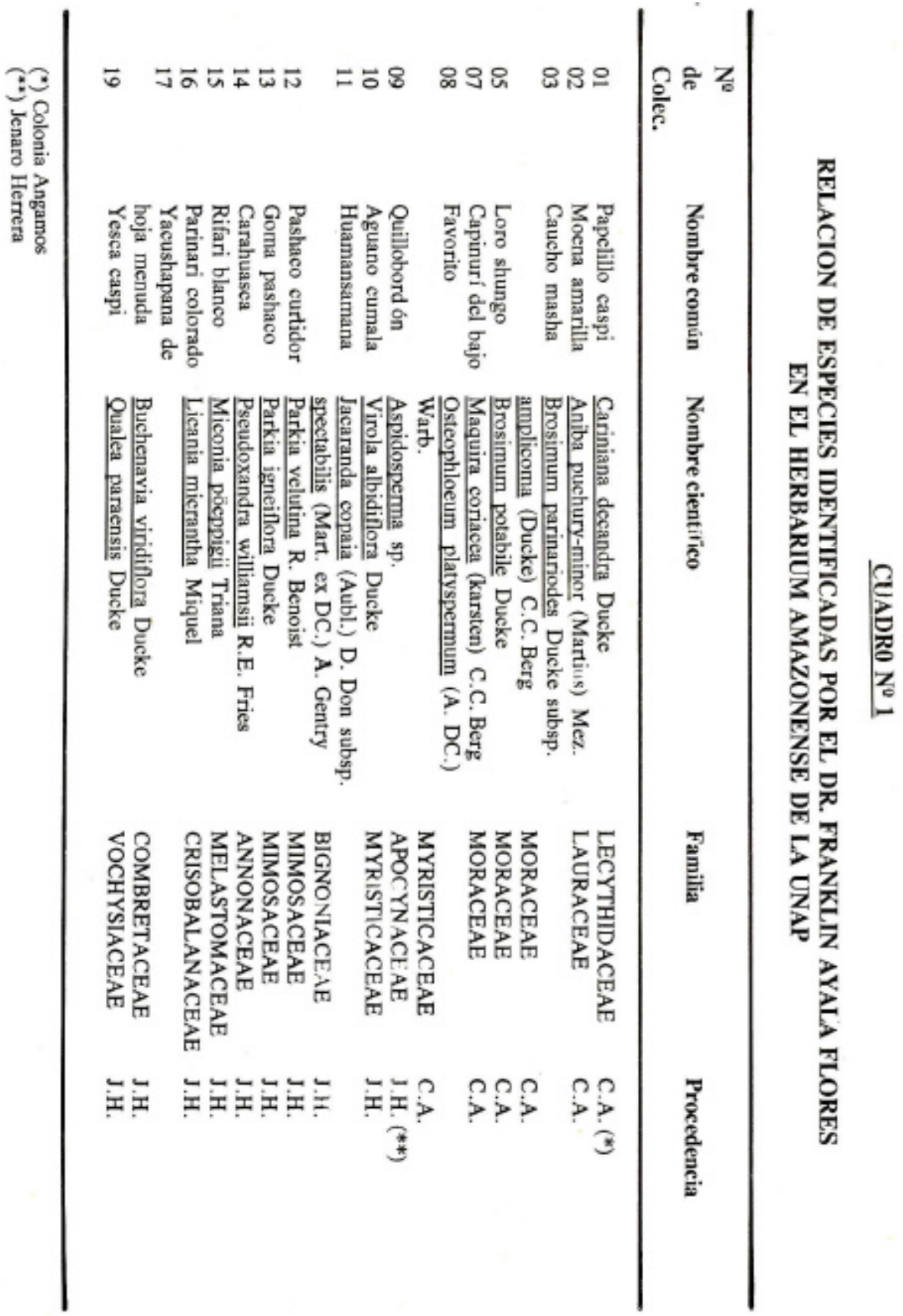




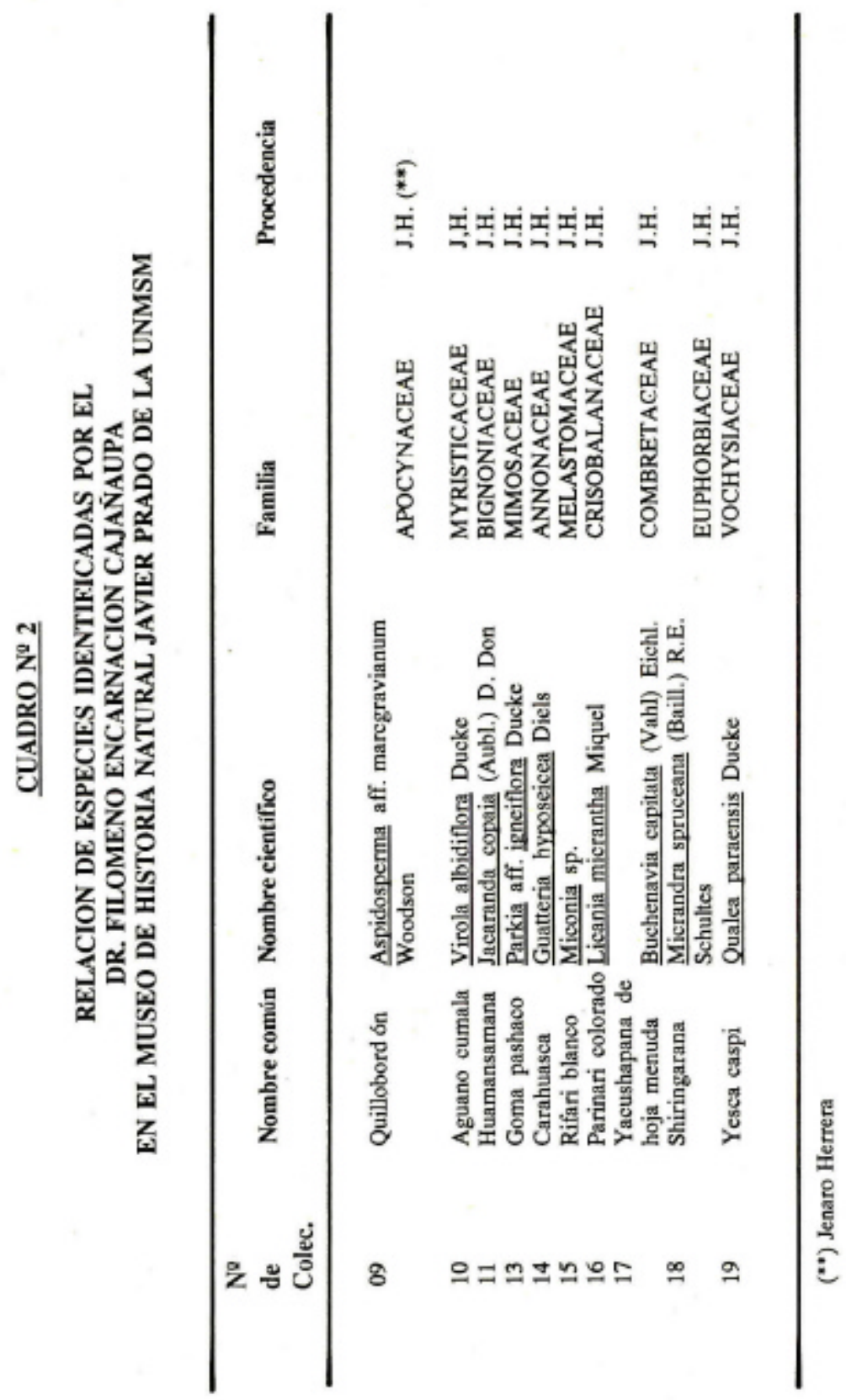




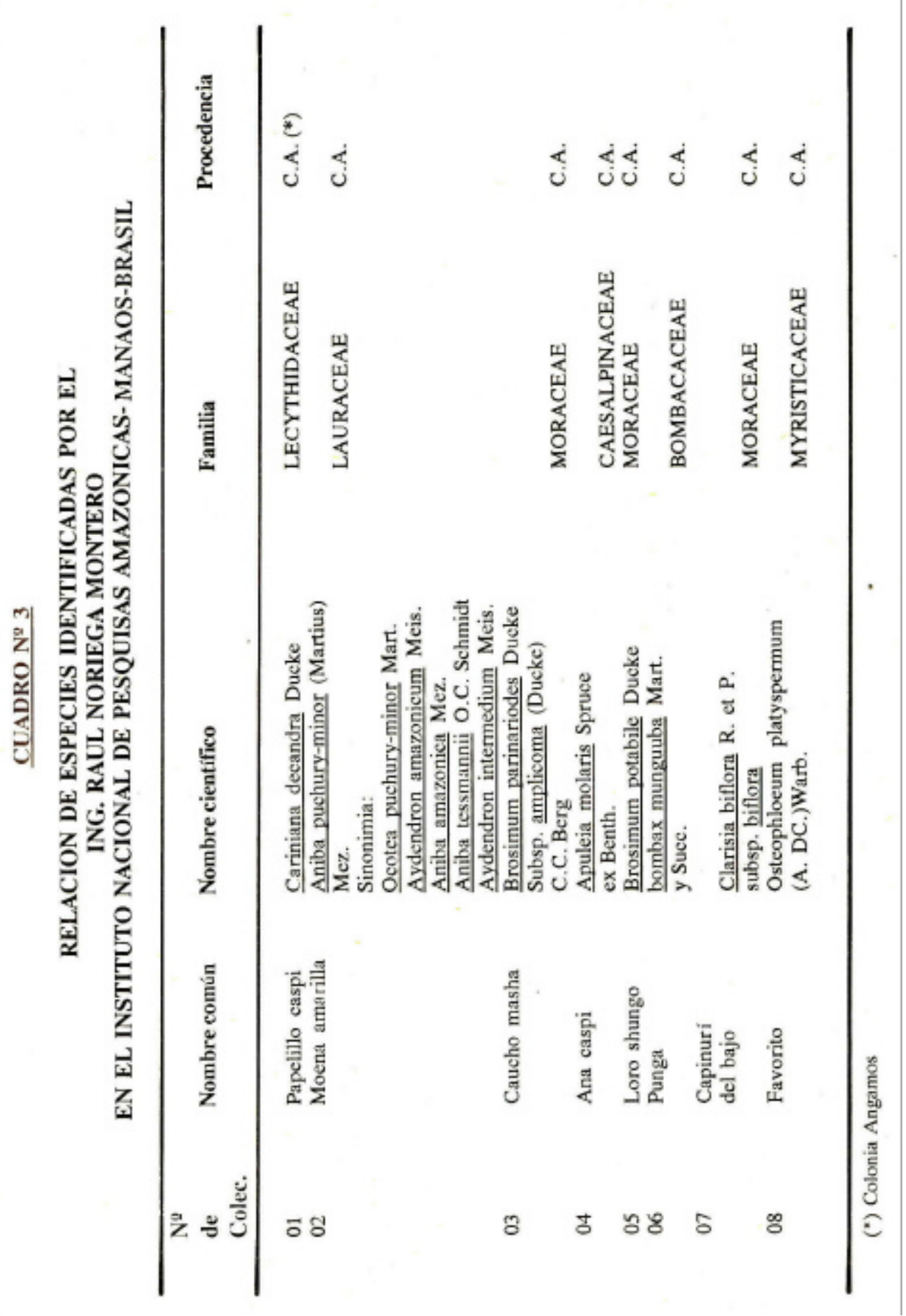




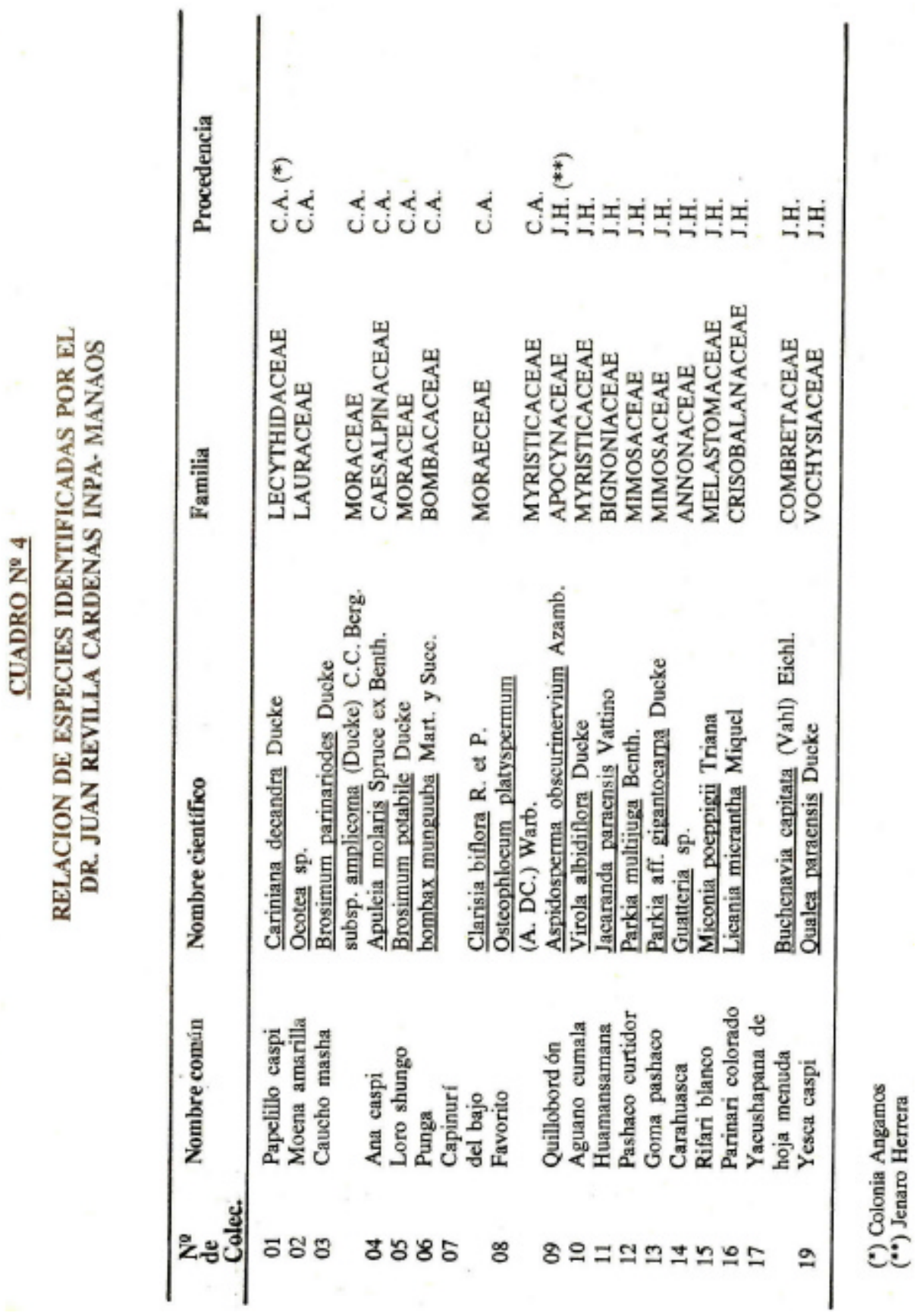




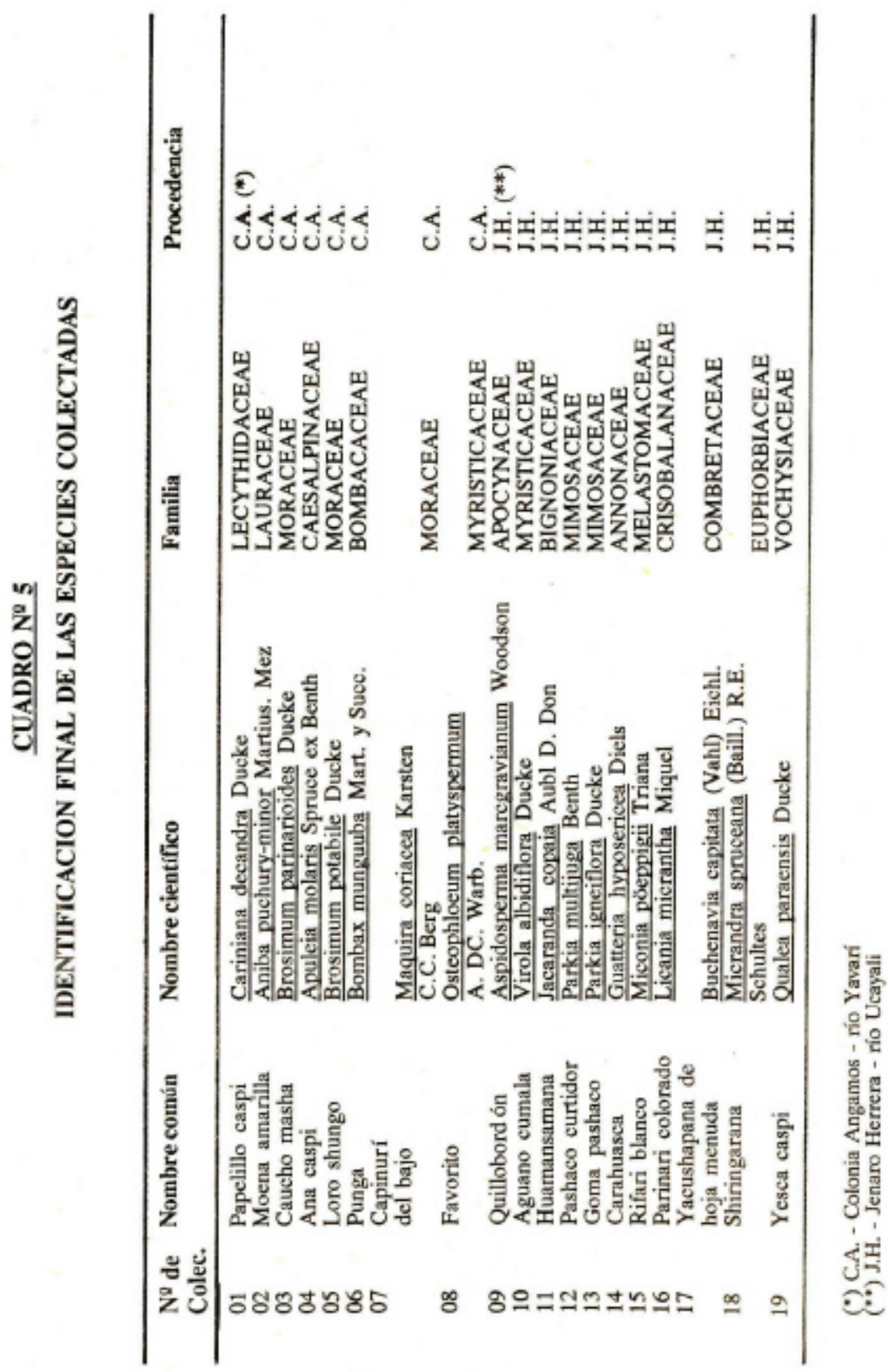




\section{B. DESCRIPCION DE LAS 19 E SPE CIES IDENTIFICADAS}

\section{Aniba puchury-minor (M art.) Mez.}

a) Sinónimo: Ocotea puchury-minor Mart.; Ayudendron amazonicum M eis.; A niba amazonica Mez.; A niba tessmannii O.C. Schmidt; Aydendron intermedium M eis. ENCARNACION (10)

b) Familia: LAURACEAE

c) Nombre vernáculo: moena amarilla, muena amarilla, miena amarilla, pichurin.

d) Resumen dendrológico: A rbol codominante, altura total $28 \mathrm{~m}$., altura comercial $20 \mathrm{~m}$. y Dap 0.80 $\mathrm{m}$. Fuste con pequeños contrafuertes basales. Corteza externa áspera con manchas grisáceas amarillentas; que corresponden a huellas que deja el ritidoma al desprenderse. Ramitas terminales rígidas, derechas, tomentosas; hojas agrupadas en el extremo de las ramitas. Inflorescencias: paniculas subterminales. Fruto: baya elipsoidal (Foto $\mathrm{N} N$ 3).

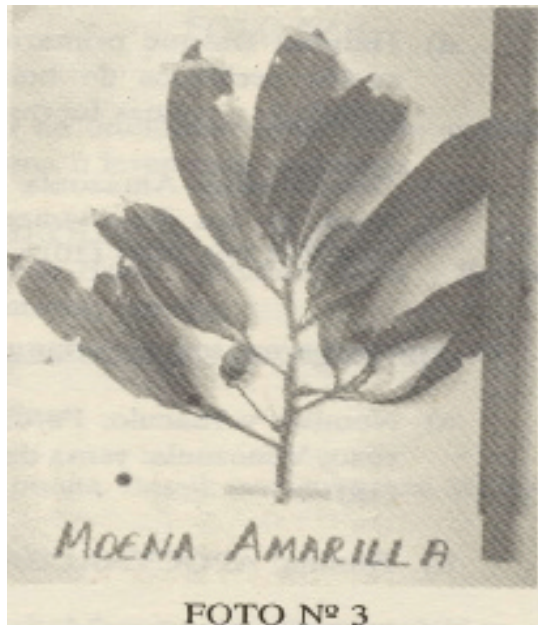

e) Habitat: Bosque primario no inundable de la amazonía peruana, sobre suelos arcillosos 0 arcillo-arenosos, de topografía plana a ondulada.

t) Distribución: BEGUIN, D.; SPICHIGER, R. y MIEGE, J. (3) indican que esta especie crece en los bosques de la amazonia central, a lo largo de los ríos; en el Perú se le encuentra en el departamento de $L$ oreto. 


\section{Apuleia molaris Spruce ex Benth.}

a) Nombre vernáculo: Perú A na, A nacaspi; Brasil: Muira-juba; Paumulato, A marelao ENCARNACION (10) y SILVA (18).

b) Familia. CAESALPINACEAE

c) Resumen dendrológico: A rbol dominante, altura total $30 \mathrm{~m}$., altura comercial $22 \mathrm{~m}$. y Dap $0.75 \mathrm{~m}$. Fuste con raíces tablares compuestas, sinuoso, robusto y torcido. Corteza externa gris parduzca, áspera, ritidoma en placas grandes e irregulares; la interna es fibrosa arenosa. Ramita terminal circular, pubescente, grisáceo; hojas compuestas, dispuestas alternadamente, imparipinnadas. Fruto legumbre aplanada de superficie aterciopelada de 7-9 semillas planas.

d) Habitat: Bosque primario no inundable, preferentemente sobre suelos arcillosos de buen drenaje, en terrenos de topografía ondulada y colinas fuertemente disectadas.

e) Distribución: A mazonia peruana, brasilera y venezolana. En el Perú, en los departamentos de L oreto, San M artín y U cayali.

ENCARNACION (10) y RECORD Y HESS (15).

3. A spidosperma marcgravianum W oodson

a) Nombre vernáculo: Perú: quillobordón; Brasil: piquiá marfin do roxo; Venezuela: yema de huevo, amarillo SILVA (18), SOUKUP (19).

b) Familia: APOCYNACEAE

c) Resumen dendrológico: A rbol de 28 $\mathrm{m}$. de altura total, altura comercial 18 m. y Dap de $0.85 \mathrm{~m}$. Base del fuste con pequeñas raíces tablares. Fuste recto 0 poco torcido, cilíndrico, ostenta una copa compacta. Corteza externa fisurada, ritidoma desprendible en placas rectangulares

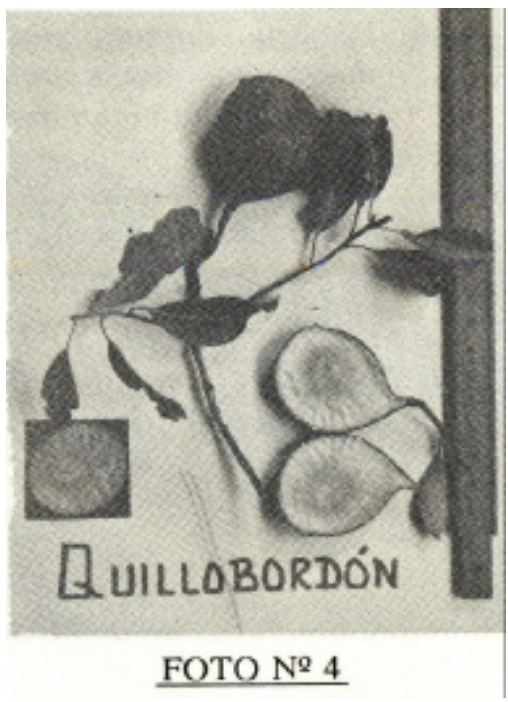


pequeñas; la interna es fibrosa-arenosa, amarillo mostaza. Ramita terminal orbicular, hojita terminal en forma de lanza; hojas simples y alternas. Inflorescencia en panículas terminales. Flores dispuestas en glomérulos libres. Fruto: Cápsula achatada, orbicular. Semillas aladas, orbiculares y desiguales, con un promedio dc 16 disemínulos por fruto. (F oto $\mathrm{N} \cong 4$ ).

d) Habitat: Bosque primario no inundable sobre suelo arcilloso, en terrenos de topografía plana o levemente ondulada.

e) Distribución: ALBUQUEROUE, B. W. P. (1) indica que se le encuentra en la amazonia de Brasil, Surinam, Perú y Bolivia. En el Perú, en el departamento de L oreto.

4 Bombax munguuba M art. y Succ.

a) Nombre vernácul o: Perú: punga. Brasil: mungubarana SIL VA (18)

b) Familia: BOM BACACEAE

c) Resumen dendrológico: Arbol dominante, altura total $25 \mathrm{~m}$., altura comercial $19 \mathrm{~m}$. y Dap $0.75 \mathrm{~m}$. Fuste retorcido y-cilíndrico. Corteza externa lisa o tenuemente fisurada; la interna es fibrosa, rojo ladrillo con jaspes longitudinales blancos. Ramita terminal anillada, verde negruzca; hojas alternas, subopuestas, digitadas, compuestas. Inflorescencia juvenil capsular: Fruto: cápsula subglobosoelipsoidal, dehiscente. Semillas 4-5 gomas. (F oto $N$ o 5).

d) Habitat: Bosque primario sobre terrenos periódicamente inundables, cerca a riachuelos y quebradas, de preferencia sobre suelos arcillosos con bastante sedimentación orgánica.

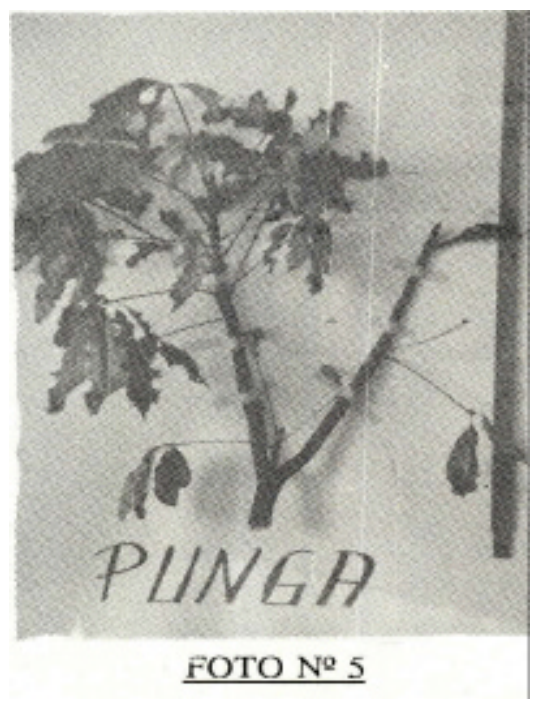


e) Distribución: A mérica Central y A mérica del Sur, desde M éxico hasta la amazonia (Noreste del Perú y Norte del Brasil) RECORD y HESS (15)

5. Brosimum parinarioides Ducke subsp. A mplicoma (Ducke) C.C. Berg

a) Sinónimo: Brosimum amplicona Ducke

b) Familia: MORACEAE

c) N ombre vernáculo: Perú: caucho masha. Brasil: amapá, amaparana.

d) Resumen dendrológico: A rbol dominante, altura total $36 \mathrm{~m}$., altura comercial $23 \mathrm{~m}$. y Dap $0.90 \mathrm{~m}$.

Base con aletas robustas, gruesas, redondeadas. Fuste recto y cilíndrico, corteza externa lenticelar; la interna es fibrosa, segrega abundante látex blanco. Ramita terminal estriada, nudosa y pulverulenta; hojas simples, semiopuestas o alternas; hojitas terminales cubiertas por estípulas amplexicaules oscuras, pubescentes y caducas. Inflorescencia axilar, semiesférica, flores amarillas agrupadas en un receptáculo verde. Fruto: pequeño, globoso, drupáceo, marrón achocolatado; una sola semilla subglo bosa más ancha que alta. (F oto $\mathrm{N} \cong 6$

e) Habitat: Bosque primario

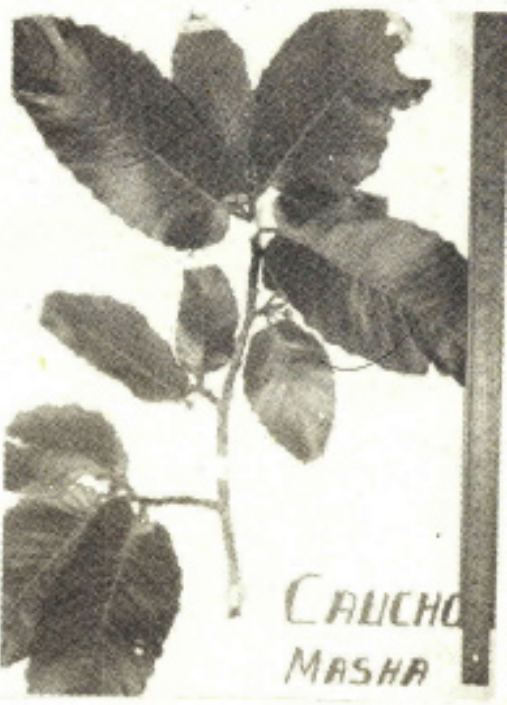

FOTO Ne6 noinundable, sobre suelos arcillosos y areno-arcillosos, en terrenos de topografía plana a ondulada.

f) Distribución: Según SPICHIGER (20) esta especie se encuentra en la cuenca superior y media del A mazonas (Perú y Brasil). En el Perú, en el D epartamento de L oreto. 


\section{Brosimum potabile Ducke}

a) Sinónimo: Brosimum myristicoides Standley

b) Familia: MORACEAE

c) Nombre vernáculo: Perú: Ioro shungo, mashonaste; Brasil: panrainha, leiteira SILVA (18).

d) Resumen dendrológico: Arbol dominante, altura total $35 \mathrm{~m}$., altura comercial $25 \mathrm{~m}$. y Dap $0.80 \mathrm{~m}$. Base con aletas robustas, gruesas y redondeadas. Fuste recto y cilíndrico. Corteza externa áspera y lenticular; la interna es fibrosa-arenosa, segrega abundante látex blanco. Ramita terminal circular, grisácea, hojita terminal con estípulas aniplexicaules; hojas simples y alternas. Inflorescencia subglobosa. (F oto $\mathrm{N} N$ ㄱ).

e) Habitat: Bosque primario no inundable, sobre suelo arcilloso, de topografía levemente ondulada 0 en terrenos planos.

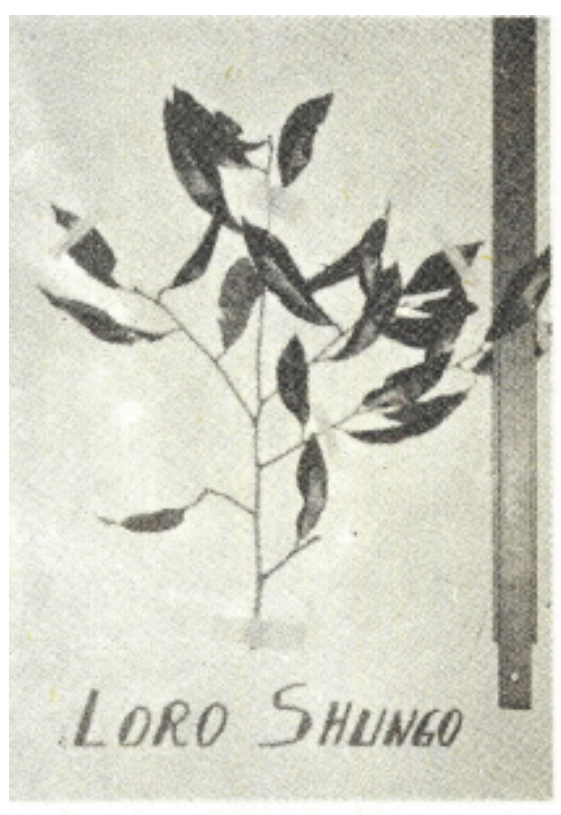

FOTO Ne7

f) Distribución: Según BERG (4) esta especie crece en la amazonía peruana y brasilera. En el Perú, en el Departamento de Loreto. 


\section{Buchenavia capitata (V ahl) Eichl.}

a) Sinónimo: Terminalia obovata Camb. RECORD y HESS (15)

b) Familia: COMBRETACEAE

c) Nombre vernáculo: Perú: yacushapana de hoja menuda; Brasil: birindiba, cuirana, merindiba, periqueteira SIL VA (18).

d) Resumen dendrológico: Arbol dominante, altura total $21 \mathrm{~m}$., altura comercial $14 \mathrm{~m}$. y Dap $0.70 \mathrm{~m}$. Base con aletas fmas, Fuste recto y cilíndrico. Corteza externa áspera, ritidoma leñoso, desprendible en placas rectangulares; la interna es astillosa, amarillenta. Ramitas terminales cubiertas por pubescencia roja; hojas agrupadas en los extremos de las ramitas, basalmente decurrentes. Inflorescencia cubierta también de pubescencia roja, en su extremo se reunen flores formando un capítulo denso. Fruto: oblongo, con el ápice ligeramente agudo. (Foto $\mathrm{N}^{\circ}$ 8).

e) Habitat: Bosque primario no inundable, sobre suelos arenosos 0 arenoarcillosos, de topografía plana.

1) Distribución: Abundante y ampliamente distribuida entre

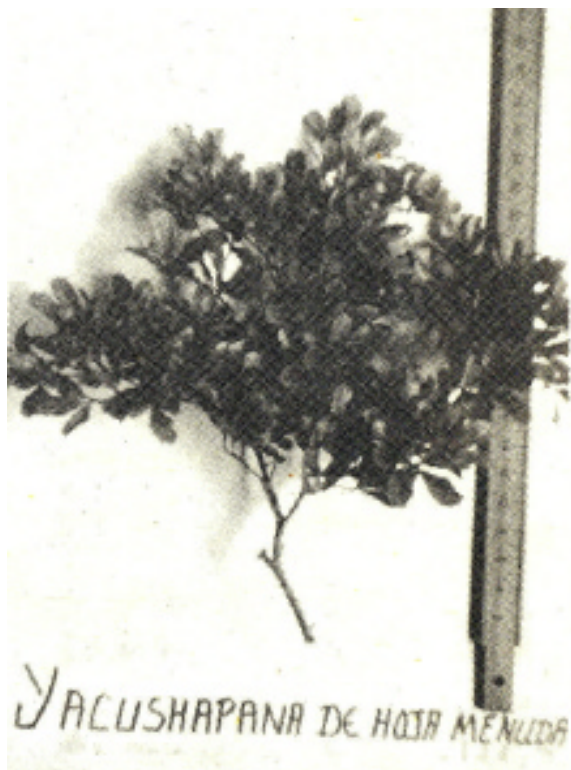

FOTO № 8 Ios trópicos, desde Cuba hasta Bolivia. SPICHIGER, ENCARNACION y STUTZ (21). 


\section{Cariniana decandra Ducke}

a) Nombre vernáculo: Perú: papelillo caspi, cachimbo, cachimbo caspi. Brasil: cerú, tauari SILVA (18) y SOUKUP (19)

b) Familia: LECYTHIDACEAE

c) Resumen dendrológico: Arbol dominante; altura total $35 \mathrm{~m}$.; altura comercial $25 \mathrm{~m}$. y Dap $0.80 \mathrm{~m}$. Base tenuemente abultada. Fuste recto, cilíndrico, algunas veces de sección cuadrada; corteza externa levemente fisurada, ritidoma leñoso, desprendible en placas rectangulares; la corteza interna se desprende en láminas largas y delgadas. Ramita terminal orbicular; hojas simples y alternas. Inflorescencia: panículas terminales. Fruto: pixidio alargado en forma de cachimbo. Semillas pequeñas con prolongación membranosa. (Foto № 9).

d) Habitat: Bosque primario no inundable, ocasionalmente en bosques húmedos de "bajial", sobre suelos casi siempre arcillosos 0 arcillo arenosos, de topografía plana a ondulada.

e) Distribución: ENCARNACION (10) esta especie crece en la amazonía de Perú y Brasil. En el Perú se le encuentra en D epartamento de L oreto.

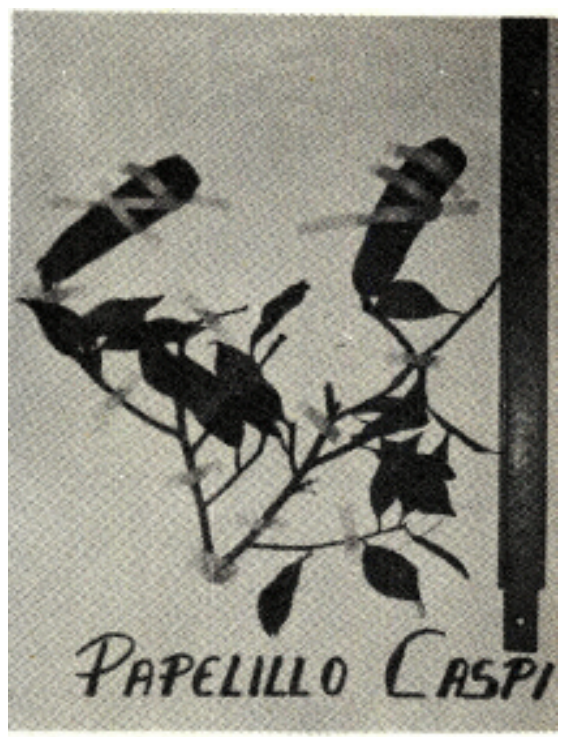

FOTO No 9 
9. Guatteria hyposericea Diels

a) Nombre vernáculo: Perú: carahuasca. Brasil: envira amarela, envira preta SILVA (18).

b) Familia: ANNONACEAE

c) Resumen dendrológico: A rbol codominante; altura total $22 \mathrm{~m}$.; altura comercial $16 \mathrm{~m}$. y Dap $0.50 \mathrm{~m}$. Base con raíces tablares pequeñas. Fuste recto y cilíndrico. Corteza externa áspera; la interna es arenosa. Ramita terminal circular; hojitas terminales conduplicadas; hojas simples, alternas. Inflorescencia: axilar. Fruto: indehiscente, ovalado, brevemente apiculado. U na sola semilla por fruto (F oto $\mathrm{N} 010$ ).

d) Habitat: Bosque primario no inundable, sobre suelos arcillosos a arcillo-arenosos, en terrenos de topografía plana.

e) Distribución: Según BERNARDI SPICHIGER esta especie se le encuentra en la amazonia peruana y brasilera. En el Perú, en L oreto.

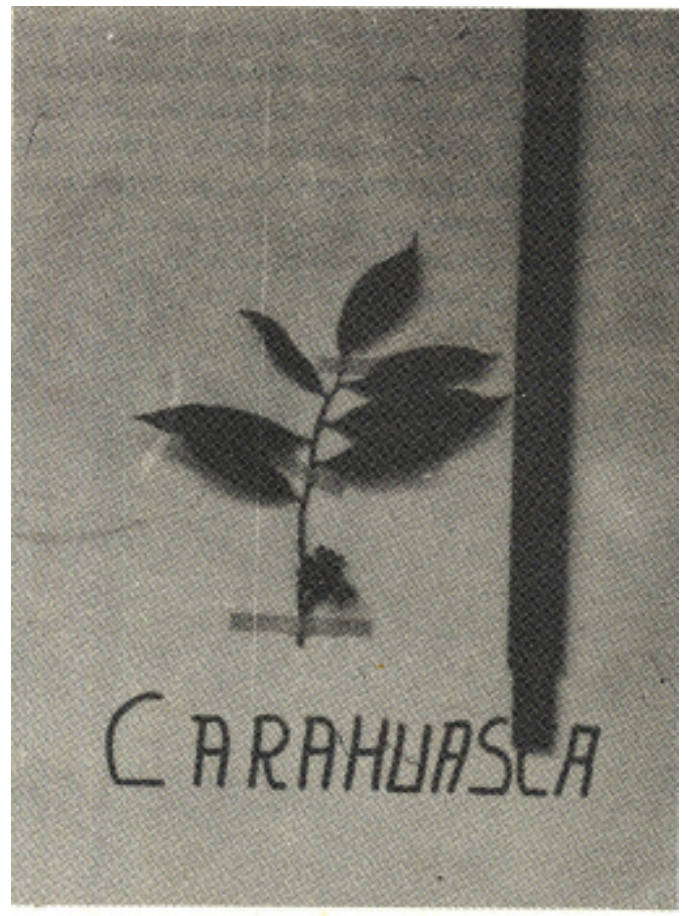

FOTO N ${ }^{2} 10$ 


\section{J acaranda copaia (A ubl.) D. Don}

Subsp. spectabilis (M art. ex DC) A. Gentry

a) Sinónimo: Jacaranda procera (Willd.) R. BR; iacaranda spectabilis M art, ex A. DC; jacaranda superba Pittier y Bignonia copaia A ubl. PI. ENCARNACION (10)

b) Familia: BIGNONIACEAE

c) Nombre vernáculo: Perú: huamansamana, ishtapi, soliman del monte, chichara caspi, pavarisco, jacarandá SOUKUP (19). Brasil: caroba, caroba manaca, carnaúba, marupá falso, caroba do mato SIL V A (18).

d) Resumen dendrológico: A rbol dominante; alt tira total $30 \mathrm{~m}$. , altura comercial 22 m. y Dap $0.70 \mathrm{~m}$. Fuste on base crónica, recta, sin ramas en su mayor longitud, cuando son jóvenes. Corteza externa tenuemente fisurada, con pequeñas lenticelas; la interna es arenosa y fibrosa. Ramita terminal cuadrangulai, hojitas terminales conduplicadas; hojas compuestas, paribipinnadas opuestas, hasta $1 \mathrm{~m}$. de largo por $0.60 \mathrm{~m}$. de ancho, con 15-20 pinnas alternas y 5-25 folio- los opuestos.

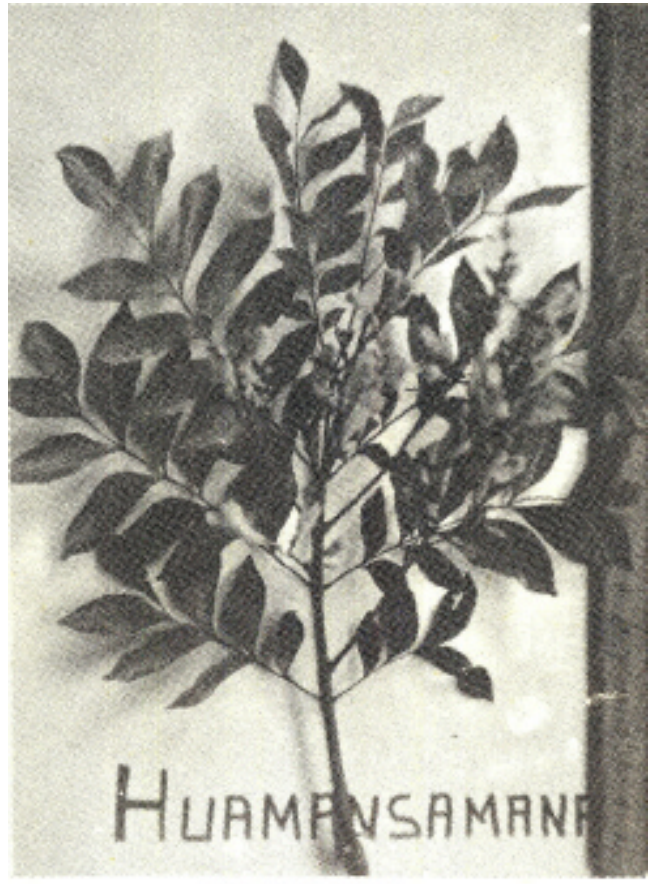

FOTO No 11

Inflorescencias: paniculas largas y terminales; flor campanulada azulviolácea-purpúrea. Fruto: capsular, plano, oval, achatado; semillas aladas que caen en la dehiscencia del fruto. (Foto $\mathrm{N} 011$ ). 
e) Habitat: Bosque primario no inundado, preferentemente sobre suelos arcillosos, de topografía plana a ondulada.

f) Distribución: Según LAO (12) es una especie ampliamente difundida en América tropical, principalmente Brasil. En el Perú se le encuentra en los Departamentos de Loreto, U cayali, Huánuco, San Martin, Paseo y M adre de Dios.

\section{Licania micrantha Miquel}

a) Nombre vernáculo: Perú: parinari colorado

b) Familia: CRISOBALANACEAE

e) Resumen dendrológico: A rbol dominante, copa compacta; altura total $23 \mathrm{~m}$., altura comercial $16 \mathrm{~m}$. y Dap $0.80 \mathrm{~m}$. Base con raíces abultadas con formaciones nudosas. Fuste recto, cilíndrico, corteza externa con lenticelas agrupadas en filas transversales, ritidoma pequeño, desprendible en escamas; la interna es arenosa. Ramita terminal circular; hojas simples, alternas, inflorescencia: panículas axilares o terminales, compuesta de espigas de címulas. Fruto: tierno, de superficie aterciopelada. (F oto $\mathrm{N} \cong$ 12).

d) Habitat: Bosque primario no inundable preferentemente sobre sue lo arcilloso 0 arcilloarenoso, de topografía plana.

e) Distribución: SPICHIGER y MASSON (22) a esta especie se le encuentra en la cuenca amazónica y Guayanas. En el Perú, en D epartamento de L oreto!

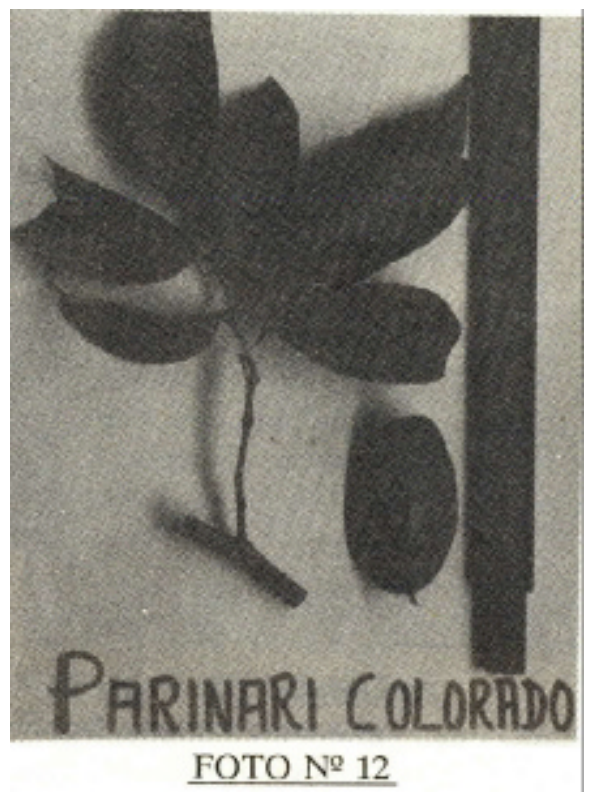




\section{Maquira coriacea (Karsten) C.C. Berg}

a) Sinónimo: Pseudolmedia coriacea Karsten; Olmediophaena coriacea (Karsten); Olmedia laurina Baillon; Olmedia oblicua Huber; Pseudolmedia oblicua (Huber) Ducke; Olmedia maxima Ducke y Olmediophaena maxima (Duckc) Ducke.

b) Familia: MORACEAE

e) Nombre vernáculo: Perú: capinurí del bajo. Brasil: muiratinga SILVA (18) y SOUKUP (19).

d) Resumen dendrológico: Arbol dominante; altura total $30 \mathrm{~m}$.; altura comercial $20 \mathrm{~m}$. y Dap $0.80 \mathrm{~m}$. Contrafuertes basales grandes y compuestas. Fuste recto o levemente torcido, cilíndrico. Corteza externa lenticelar, áspera; la interna es arenosa-fibrosa, exuda abunadante latex.

A marillento. Ramita terminal orbicular, grisáceo; hojita terminal cubierta por estípulas curvas; hojas simples, alternas. Inflorescencia: globosa a subglobosa. Fruto: elipsoide o globoso con una semilla. (Foto $\mathrm{N} \cong$ 13).

e) Habitat: Bosque primario, periódica 0 permanentemente inundable, sobre suelo arcillo-arenoso, de topografía plana.

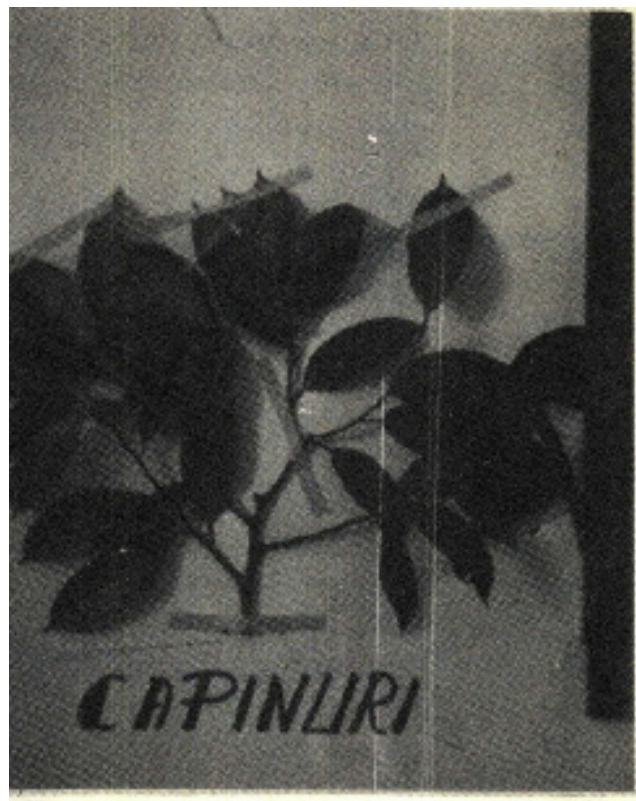

FOTO № 13

f) Distribución: Según BERG (4) esta especie está distrihuída en la amazonía peruana, brasilera, venezolana y colombiana. En el Perú, en el Departamento de $L$ oreto. 


\section{M iconia pöeppigli Triana}

a) Nombre vernáculo: Perú: rifan blanco. Brasil: buxixu canela de velho, canela de velho, taquari SILVA (18).

b) Familia: MELASTOMACEAE

c) Resumen dendrológico: A rbol codominante; al tura total $16 \mathrm{~m}$., altura comercial $9 \mathrm{~m}$. y Dap $0.50 \mathrm{~m}$. Base con raíces tablares bajas. Fuste acanalado en la base y cilíndrico en la parte alta. Corteza externa poco áspera; la interna es fibrosa-arenosa, con jaspes longitudinales blancos, segrega escasa resma cristalina. Ramita terminal ligeramente comprimida-cuadrada, verde claro; hojitas terminales en forma de lanz; hojas simples, opuestas. Inflorescencia: paniculas terminales. Fruto: baya poiisperma con semillas piramidales. (F oto $\mathrm{N} N 14$ ).

d)

Habitat:

secundarios

inundable,

preferentemente sobre suelos arcillos, de topográfia plana

e) Distribución: Según RECORD y HESS (15) esta especie está distribuída en la región amazónica del Perú y Brasil. En el Perú se le encuentra en los Departamentos de L oreto, Huánuco y San Martín.

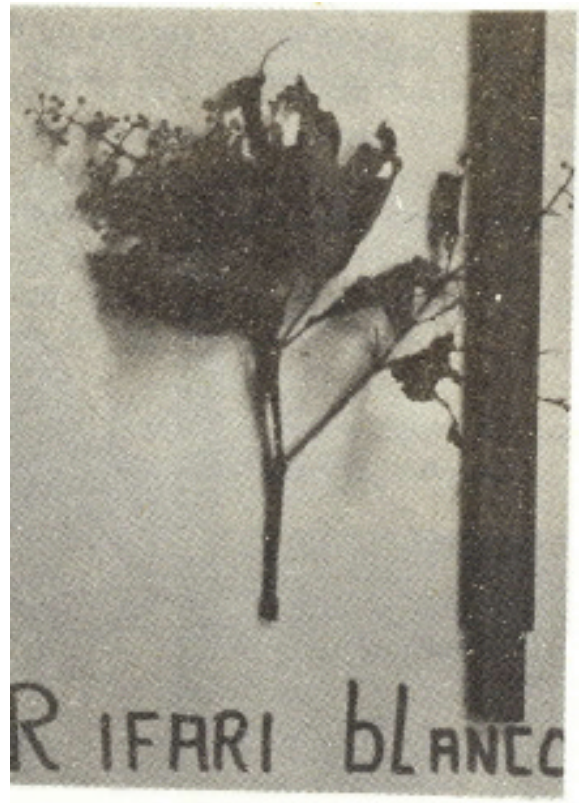

FOTO № 14 
14. Micrandra spruceana (Baill.) R.E. Schultes

a) Nombre vernáculo: Perú: shiringarana. Brasil: arvore de mamona.

b) Familia: EUPHORBIACEAE

c) Resumen dendrológico: A rbol dominante; altura total $33 \mathrm{~m}$., altura comercial $21 \mathrm{~m}$. y Dap $0.70 \mathrm{~m}$. Base con raíces volantes compuestas. Fuste recto, de sección ligeramente cuadrada. Corteza externa áspera, ritidoma desprendible, en placas pequeñas o irregularmente; la interna estratificada, exuda abundante látex amarillo-arenoso. Ramita terminal circular, anillada; hojita terminal ocráseo. Hojas simples, alternas. Inflorescencias: con flor diminuta. Fruto: globoso. (F oto $\mathrm{N} \cong 15$ ).

d) Habitat: Bosque primario no inundable, sobre suelo arenoso 0 areno-arcilloso, en terreno de topografía plana.

e) Distribución: Según RECORD $y$ HESS (15), esta especie está ampliamente distribuída desde $\checkmark$ enezuela hasta la amazónica al sureste de Brasil. En el Perú se le encuentra en el Departamento de L oreto.

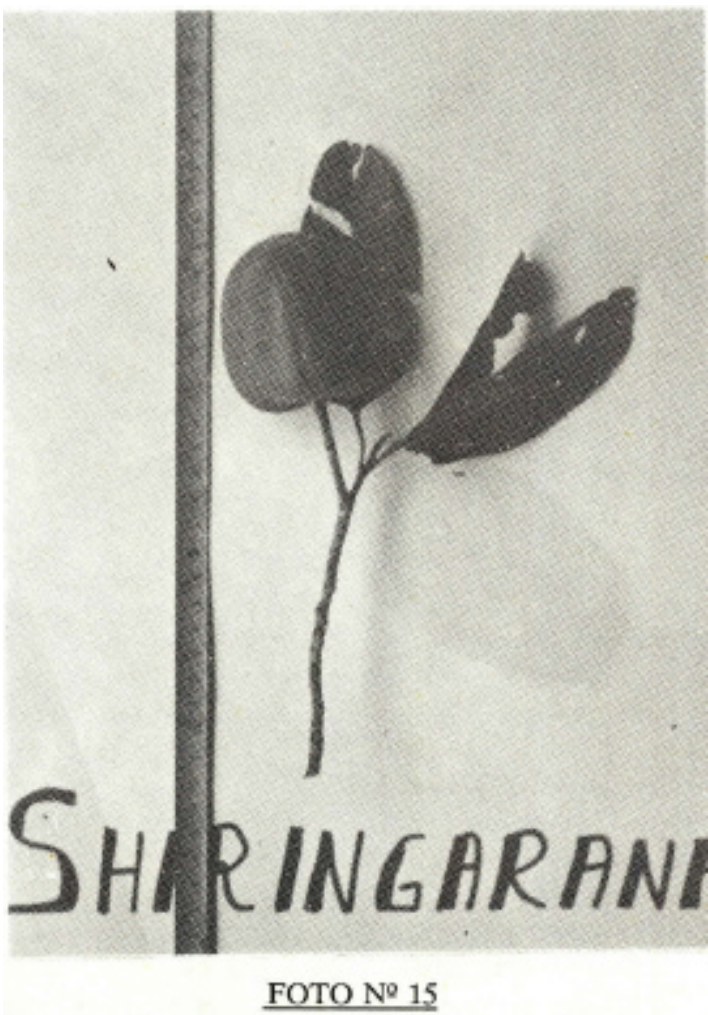




\section{Osteophloeum platyspermum (A. DC.) Warburg}

a) Nombre vernáculo: Perú: favorito, dumala blanca. Brasil: ucuubarana. Colombia: chalviande EN CARN A CION (10)

b) Familia: MYRISTICACEAE

c) Resumen dendrológico: A rbol dominante; altura total $35 \mathrm{~m}$., altura comercial $25 \mathrm{~m}$. y Dap $0.70 \mathrm{~m}$. Fuste recto hasta el suelo, cilíndrico. Corteza externa esponjosa; la interna fibrosa, exuda abundante savia rojo-ámbar-acaramelado. Ramita terminal cilíndrica, asurcada y densamente puberulenta; hojas simples y alternas. Inflorescencia: panículas axilares; flores con bractéolos deciduas en la base. Fruto: capsular, con una semilla dos veces más ancha que alta. (F oto $\mathrm{N} \cong 16$ ).

d) Habitat: Bosque primario no inundable, preferentemente sobre suelo arcilloso, de topografía plana o levemente ondulada.

e) Distribución:

Según BERNARDI

y SPICHIGER (6)

a esta especie se le encuentra en

$\checkmark$ enezuela,

Colombia Perú, Brasil y Guyana (ex- Británica). En el Perú se le encuentra en los Departamentos de L oreto, San M artín Huanuco U cayali.

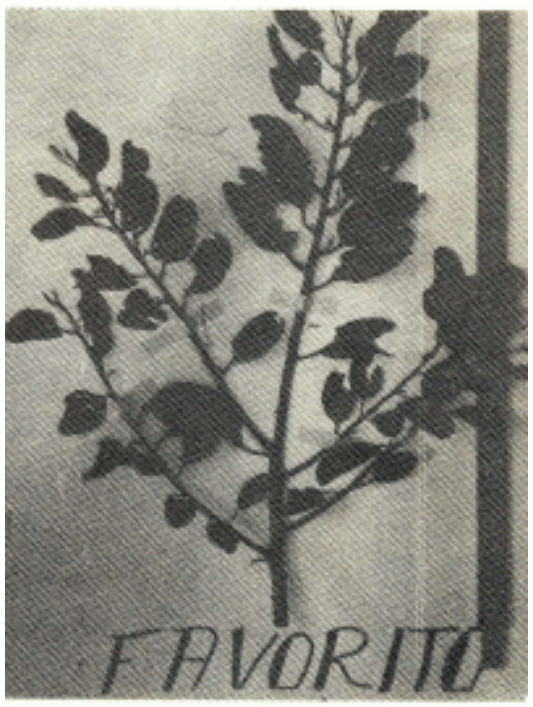

FOTO Ne 16 


\section{Parkia igneiflora Ducke}

a) Nombre vernáculo: Perú: goma pashaco, goma huayo

b) Familia: M IM OSA CEAE

c) Resumen dendrológico: A rbol dominante; altura total $25 \mathrm{~m}$., altura comercial $18 \mathrm{~m}$. y Dap $0.65 \mathrm{~m}$. Base con raíces tablares, compuestas. Fuste recto, algunas veces semitorcido, cilíndrico. Corteza externa áspera, lenticelas agrupadas en filas transversales; la interna laminar fibrosa, segrega lentamente resma café, con leche poco cristalina. Ramita terminal cuadrada, verde claro; hojitas terminales convolutas; hojas compuestas, opuestas y bipinnadas. Inflorescencia: panículas terminales. Flores sésiles. Fruto: legumbre chata con 15-18 semillas. (Foto $\mathrm{N} N \mathbf{1 7}$ ).

d) Habitat: Bosque primario no inundable, preferentemente sobre terreno con buen drenaje, suelos arcillosos, planos 0 poco ondulados.

e) Distribución: Según BERNARDI, ENCARNACION y SPICHIGER (5), a esta especie se le encuentra en la amazonía peruana, brasilera y venezolana. ENCARNACION (10) indica que en el Perú crece en los Departamentos de L oreto y U cayali.

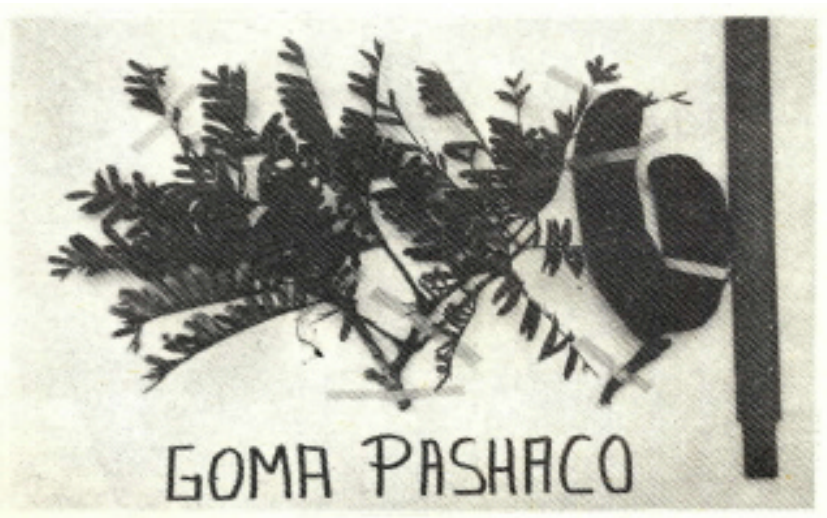

FOTO № 17 


\section{Parkia multijuga Benth}

a) Nombre vernáculo: Perú rashaco curildor, pashaco colorado. Brasil: faveira, vlsqueiro SILVA (18)

b) Famita: MIM OSA CEAE

c) Resumen dendrológico: A rbol dominante: altura total 26 ni., altura coniercai 17 ni. Y Dap 0.80 ni. Base con raíces redondas, Fuste semi-recto, cilindríco. Corteza externa áspera, ritidoma desprendible en escamas pequeñas; la interna fibrosa, exuda resma amarillenta, poco transparente. Ramita terminal cuadráda, marrón verdoso; hujitas terminales conduplicadas; hojas, inflorescencias y frutos finamente velutino-ferrugíneos. Hojas compuestas, alternas y bipinnadas. Inflorescencia: capítulos globosos en panículas axilares; flores sésiles. Fruto: legumbre aplanada y recurvada con $15-20$ semillas. (F oto $\mathrm{N} N 18$ ).

d) Habitad: Bosque primario en terrenos no inundables, con buen drenaje, referentemente sobre suelos arcillosos, de topografía plana.

e) Distribución: Según BERNARDI, EN ENCARNACION Y SPICHIGER (5), a esta especie se le encuentra en la amazonia y en las guayanas.

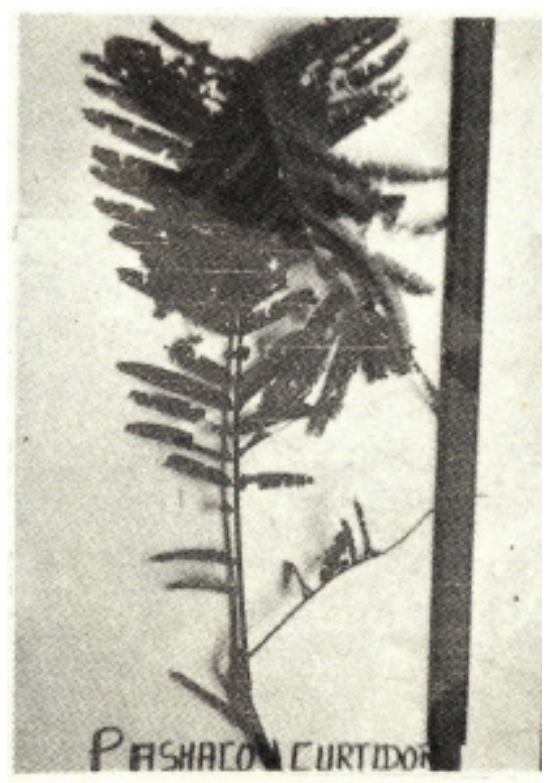

FOTO № 18 
18. Qualea paraensis Ducke

a) Nombre vernáculo Perú: yesca caspi. Brasil: mandioqueira, lacreiro SILVA (18)

b) Familia: VOCHY SIACEAE

c) Resumen dendrológico: Arbol dominante; altura total 30 m., altura comercial $20 \mathrm{~m}$. y Dap $0.75 \mathrm{~m}$. Base con raíces tablares trapezoidales altas. Fuste recto y cilindríco, corteza externa fisurada; ritidoma desprendible en placas rectangulares o irregularmente; la interna es fibrosa-arenosa. Ramita terminal circular, versa; hojitas terminales conduplicadas; hojas simples o subopuestas con estípulas nectarias extraflorales, nervadura secundaria perpendicular al nervio principal. Inflorescencia: panículas terminales o situado en las axilas de las hojas terminales. Fruto: cápsula aovado-elípticas, dehiscente por tres valvas con varias semillas aladas. (Foto $\mathrm{N} N \mathbf{1 9}$ ).

d) Habitat: Bosque primario no inundable, sobre suelo arcilloso 0 arcillo - arenoso de topografía plana.

e) Distribución: Según BERNARDI y SPICHIGER (8) se le encuentra en la región amazónica del Perú y Brasil y en las Guayanas. En el Perú, en el D epartamento de L oreto .

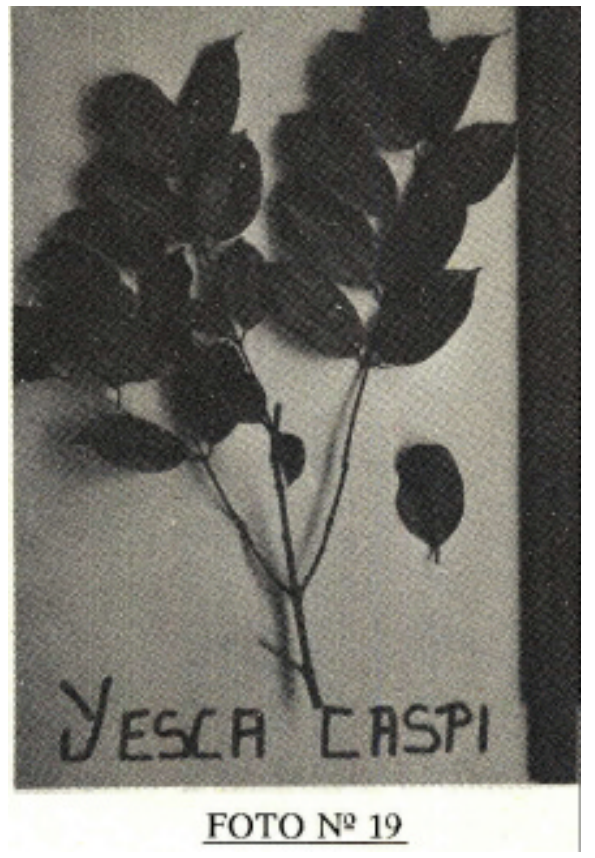




\section{Virola albidiflora Ducke}

a) Sinónimo: Virola duckei A.C.; virola kukachkana L. O. Williams

b) Familia: MYRISTICACEAE

e) Nombre vernáculo: Perú: aguano cumala, cumala caupuri. Brasil: ucuiña amarela SILVA (18) y SOU KUP (19).

d) Resumen dendrológico: A rbol dominante; altura total 28 m., altura comercial $18 \mathrm{~m}$. y Dap $0.80 \mathrm{~m}$. Base con aletas. Fuste recto y cilíndrico. Corteza externa áspera, marrón; la interna es fibrosa arenosa, segrega sabia acaramelada con tendencia rojiza. Ramita terminal algo comprimida, con pubescencia ferrugínea; hojas simples, al ternas. Inflorescencia: panículas tomentosas. Fruto: elipsoidal. ( $F$ oto $\mathrm{N} \cong 20$ ).

e) Habitat: Bosque primario no inundable o permanentemente inundable (bajiales), en las márgenes de cochas y ríos, sobre suelos con abundante materia orgánica en descomposición, topografía plana.

f). Distribución: BERNARD1 y SPICHIGER (6) indican que crece en la amazonía centro- occidental (Brasil, Perú y Colombia). ENCARNACIQN (10), indica que en el Perú se le encuentra en D epartamento de L oreto.

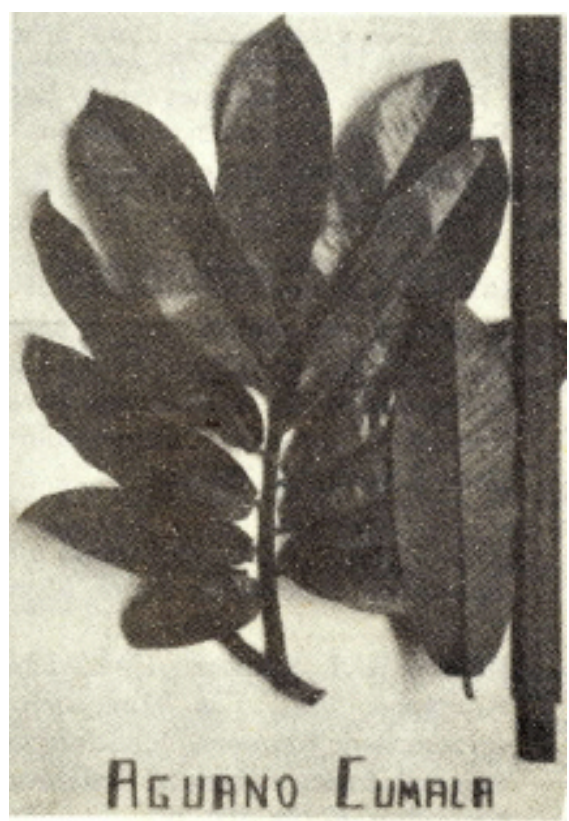

FOTO No 20 


\section{CONCLUSIONES}

A. Se identificó las 19 especies forestales que se indican en el Cuadro №5

B. Con muestras botanicas estériles es posible identificar las especies forestales, observando sus caracteristicas vegetativas más sobresalientes.

\section{BIBLIOGRAFIA}

1. Albuquerque, B. W. P. 1971. Contribuicao ao conhecimento das Aspidosperma da Amazónia brasileira (A pocynaceae). M anaus-Brasil, Instituto Nacional de Pesquisas Amazónicas (Editado en Portugués). Acta A mazónica V 1 (3): 9.17.

2. BALUARTE, Juan. 1986. Informe final del Sub-Proyecto "Identificación y Colección de $M$ aderas de las Especies Forestales del bósque húmedo Tropical (bh-T) Colonia Angamos río Y avarí y Jenaro Herrera. Iquitos. Instituto de Investigaciones de la A mazonia Peruana - Región A graria XXII-L oreto. $113 \mathrm{p}$.

3. BEGUIN, Denisse; SPICHIGER, Rodolphe y MIEGE, Jacques. 1985. Las Lauraceas del Arboretum Jenaro Herrera (provincia de Requena, departamento de Loreto, Perú); Contribución al estudio de la flora y de la vegetación de la amazonia peruana VIII. Suiza. Editado en Inglés, Francés y Español. Conservatoire et Jardin Botaniques de Géneve. Candollea 40 (1): 253-304.

4. BERG, C.C. 1972. Moraceae; Olmediae and Brosimeae, IN; Flora neotrópica. Editado en Inglés, M onografía \# 7. 156 p.

5. BERNARDI, Luciano; ENCARNACION, Fiomeno y SPICHIGER, Rodolphe. 1981. Las M iniosoideas del A rboretum Jenaro Herrera (Provincia de Requena, departamento de Loreto, Perú). Suiza. Editado en Español, inglés y francés. Conservatoire et J ardin Botaniques de Géneve.Candollea 36 (2): 301-383. 
6. BERNARDI, L. y SPICHIGER, R. 1980. Las M iristicaceas del Arboretum J enaro Herrera. Suiza. Editado en Español y Francés. Consevatoire et Jardin Botaniques de Géneve. Candollea 35 (1): 33-182.

7. $\quad$--.-1981. Las A nnonaceas del Arboretum Jenaro Herrera (Provincia de Requena, departamento de L oreto, Perú). Suiza. Editado en Español, Inglés y F rancés. Conservatoire et J ardin botaniques de Géneve. Candollea 35 (2): 341-383.

8. BERNARDI, L. y SPICHIGER, R. 1981. Ias Vochysiaceas del A rboretum Jenaro Herrera (provincia de Requena, departamento de Loreto, Perú). Suiza. Conservatoires et J ardin Botaniques de Géneve. Candollea 36 (1): 131-144.

9. BUDOWSKY, Gerardo. 1954. La identificación en el campo de los árboles más importantes de la A mérica Central. Turrialba-Costa Rica. Tesis M agister A grícola. Instituto Interamericano de Ciencias A grícolas. 326p.

10. ENCARNACION, Filomeno. 1983. Nomenclatura de las especies forestales comunes en el Perú. Lima. Documento de Trabajo № 7. Fortalecimiento de los Programas de Desarrollo Forestal en Selva Central. Proyecto PNUD/FAO/PER/81/002. 149 p.

11. JIMENEZ. H. 1970. Los árboles más importantes de la serranía de San L ucas. M anual de identificación en el campo. Bogotá-Colombia. Instituto de Desarrollo de los Recursos Naturales R enovables. 240p.

12. LAO, Rafael. 1985. Estudio dendrológico de las especies forestales de Y urimaguas (L oreto). Lima-Perú. Universidad N acional A graria-L a M olina. $40 \mathrm{p}$.

13. MARENGO, José. 1983. Estudio agroclimático en la zona de Jenaro Herrera (Requena-Loreto) y climático en la selva baja norte del Perú. Lima-Perú. Tesis para optar el título de Ing. M eteorólogo. U niversidad N acional A grariaL a M oliña. 440 p.

14. OFICINA NACIONAL DE EVALUACION DE RECURSOS NATURALES (ONERN). 1975. Inventario, evaluación e integración de los recursos naturales de la zona Iquitos, Nauta, Requena y Colombia Angamos. LimaPerú. $269 \mathrm{p}$. 
15. RECORD, S. y HESS, W. 1943. "Timbers of the World". New Haven (E ditado en Inglés). Y ale University Press, First publised. 640 p.

16. RIOS, José. 1979. Claves preliminares de identificación con características vegetativas de 51 especies forestales del Arboreto Jenaro Herrera. LimaPerú. Tesis para optar el título de Ing. Forestal. Universidad Nacional A graria-L a M olina. 238 p.

17. SALAZAR, A. 1967. M étodos de colección de especímenes para herbario y muestras de madera de árboles forestales. Lima-Perú. Sin edición numerada. Instituto de Investigaciones Forestales-Servicio Forestal y de Caza. Universidad N acional A graria-L a M olina. $15 \mathrm{p}$.

18. SILVA, M. F. da; et all. 1977. Nomes vulgares de plantas amazonicas. $M$ anaus-Brasil. Sin edición numerada. Conselho Nacional de Desenvolvimento Científico e Tecnológico (CNPq) - Instituto Nacional de Pesquizas de A mazónia (IN PA ) - M anaus-Brasil. 222 p.

19. SOUKUP, J. 1970. V ocabulario de los nombres vulgares de la flora peruana. Lima-Perú. Sin edición numerada. Colegio Salesiano. 380 p.

20. SPICHIGER, R. 1983. Las Moraceas del A rboretum Jenaro Herrera (provincia de Requena, departamento de Loreto-Perú); contribución al estudio de la flora y de la vegetación de la amazonia peruana III. Suiza. Editado en Español, Francés e Inglés. Conservatoire et Jardin Botaniques de Géneve. Candollea 38 (1): 17-79.

21. SPICHIGER, R., ENCARNACION, F. y STUTZ, L. 1983. Las Combretaceas y Rizoforaceas del Arborctum Jenaro Herrera (provincia de Requena, departamento de Loreto-Perú); contribución al estudio de la flora y de la vegetación de la amazonia peruana III. Suiza. Editado en Español, F rancés de Inglés. Conservatoire et Jardin Botaniques de Géneve. Candollea 38 (1): 1-15.

22. SPICHIGER, R. y MASSON, D. 1984. Las Crisobalanaceas del A rboretum Jenaro Herrera (provincia de Requena, departamento de Loreto, Perú); contribución al estudio de la flora y de la vegetación de la amazonia peruana III. Suiza. Editado en Español, Francés e Inglés. Conservatoire et Jardin Botanique de Géneve. Candollea 39 (1): 13-43. 